\title{
Six novel connexin32 (GJB 1) mutations in X-linked Charcot-Marie-Tooth disease
}

\author{
M-J Lee, I Nelson, H Houlden, M G Sweeney, D Hilton-Jones, J Blake, N W Wood, \\ M M Reilly
}

J Neurol Neurosurg Psychiatry 2002;73:304-306

X-linked Charcot-Marie-Tooth disease (CMTX) is a clinically heterogeneous hereditary motor and sensory neuropathy with X-linked transmission. Common clinical manifestations of CMTX, as in other forms of Charcot-Marie-Tooth disease (CMT), are distal muscle wasting and weakness, hyporeflexia, distal sensory disturbance, and foot deformities. Motor nerve conduction velocity is reduced. In male patients it is often less than $38 \mathrm{~m} / \mathrm{s}$ in the median nerve $/$ a value often used to distinguish between "demyelinating" and "axonal" forms of CMT), but in female patients conduction velocity may be faster than this or normal. Mutations in the connexin32 (gap junction protein $\beta 1$ (GJB 1)) gene are responsible for the majority of CMTX cases. This report describes six British CMTX families with six novel mutations (four missense, one nonsense, and one frame shift) of the GJB1 gene. Affected members in these six families had typical signs of CMT but in some affected members of three families there was additional central nervous system involvement or deafness in the absence of any other explanation other than CMT.

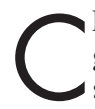
harcot-Marie-Tooth disease (CMT) is a clinically and genetically heterogeneous hereditary motor and sensory neuropathy characterised by distal muscle wasting and weakness, sensory disturbance, hyporeflexia, and foot deformities. It is a common disorder with a population frequency of about $1: 2500 .{ }^{1}$ CMT is broadly classified into type l (demyelinating, median motor nerve conduction velocity $(\mathrm{MCV})<38 \mathrm{~m} / \mathrm{s}$ ) and type 2 (axonal, $\mathrm{MCV}>38 \mathrm{~m} / \mathrm{s}$ ). ${ }^{2}$ The most common mode of inheritance for both type 1 and type 2 is autosomal dominant but some CMT families have X-linked inheritance (CMTX). CMTX patients have features of both type 1 and type 2 , although some have mild central nervous system (CNS) involvement. ${ }^{3-4}$ Results of electrophysiological studies in patients with CMTX are variable with MCVs in affected males usually either in the demyelinating range or in the intermediate range. Females are usually more mildly affected with MCVs that can be either in the intermediate or in the axonal range, or can be normal..$^{5-9}$ Undue reliance on neurophysiological findings in female patients may lead to a delay in diagnosis, especially if they are in the axonal range and a family member has been given a misdiagnosis as probable autosomal dominant CMT type 2 .

The connexin32 (gap junction protein $\beta \mathrm{l}, \mathrm{GJBl}$ ) gene is one of the genes responsible for CMTX. ${ }^{10-12}$ To date 230 mutations of GJBl gene have been reported to cause CMTX (the Inherited Peripheral Neuropathies Mutation Database is available at http://molgen-www.uia.ac.be/CMTMutations/). Mutations of the GJBl gene are widely distributed over the entire gene. In this report, we describe the clinical and electrophysiological features of six patients with CMTX, in whom we identified six novel GJBl mutations.

\section{PATIENTS AND METHODS Patients}

Six families with inherited neuropathy were studied. All families originated from the south of England. Ethical approval for genetic studies in neuropathy had been obtained from the National Hospital for Neurology and Neurosurgery Ethics Committee.

Table 1 presents the clinical and electrophysiological details. All index cases of the disease had been diagnosed as probable CMT based on typical clinical features of distal wasting, weakness, hyporeflexia with distal sensory disturbance in most patients, and a positive family history. In five index cases the chromosome 17 duplication had been excluded previously. In the sixth index case the median MCV was $32 \mathrm{~m} / \mathrm{s}$ and a nerve biopsy suggested an axonal neuropathy, so GJBl was thought to be the most likely cause and was screened for first. The first five index cases were chosen for GJBl mutation screening because the chromosome 17pl1.2 duplication was negative and the electrophysiological findings were compatible with CMTX (demyelinating/intermediate in males, axonal/ intermediate in females) and there was no male to male transmission in any family.

\section{METHODS}

DNA was extracted from leucocytes using a standard phenolchloroform method. ${ }^{13}$ The coding region of the GJBl gene was amplified using primers reported by Bergoffen et al..$^{10}$ The annealing temperature for polymerase chain reaction was $56^{\circ} \mathrm{C}$ to $53^{\circ} \mathrm{C}$ in a touch down protocol (that is, reduced $0.1^{\circ} \mathrm{C}$ per cycle) for 25 cycles and then was held constant at $53^{\circ} \mathrm{C}$ for 12 cycles. The sequencing reactions were carried out using the polymerase chain reaction primers and BigDye Terminator cycle sequencing chemistry (Applied Biosystems, Foster City, California, USA). Sequences were analysed on an ABI377 automated DNA sequencer (Applied Biosystems).

\section{RESULTS}

Direct sequencing of the GJBl gene in these six patients identified six novel mutations. As table 1 shows, the six mutations were four missense, one nonsense, and one frame shift mutation. Both W24C (missense) and T55R (missense) are highly conserved amino acids among GJB1 and other gap junction protein sequences (such as GJB3 and GJB4) in Xenopus laevis, chicken, and all mammals. V125D (missense) and F153S (missense) are also highly conserved in the GJBl proteins among all mammalian species. These mutations were not present in 50 normal controls. In families 1, 3, and 5, DNA

Abbreviations: CMT, Charcot-Marie-Tooth disease; CMTX, X-linked Charcot-Marie-Tooth disease; CNS, central nervous system; GJB 1, gap junction protein $\beta 1$; MCV, motor nerve conduction velocity; MRI, magnetic resonance image 


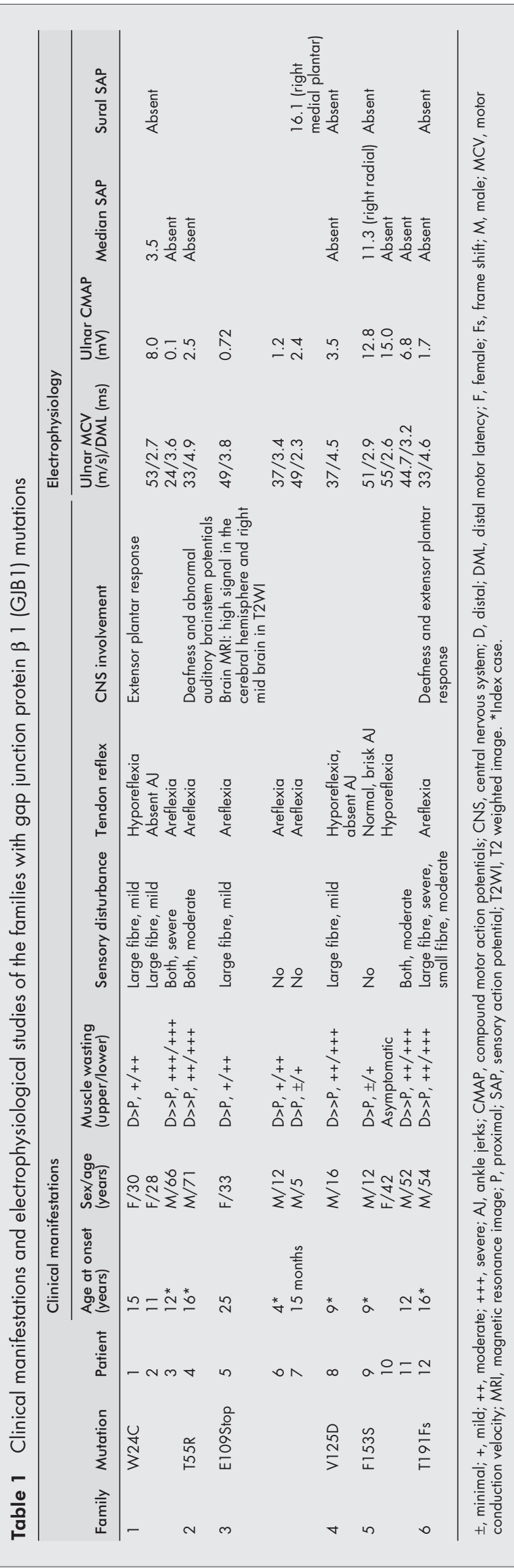

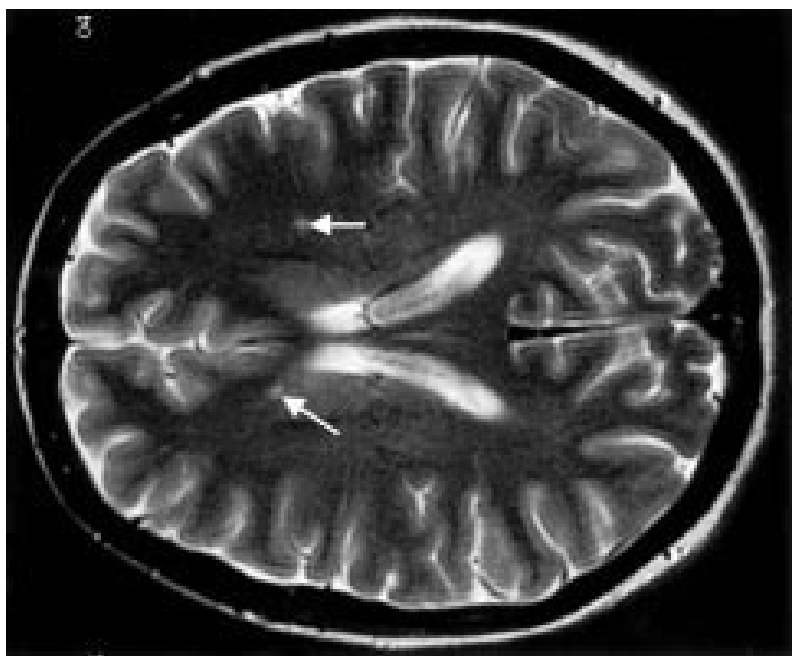

Figure 1 Magnetic resonance image of the brain of patient 5, family 3 . There are non-specific but definitely pathological white matter lesions (arrows)

from other affected members was available and the appropriate mutation was confirmed in each affected patient.

Clinically, the affected patients were similar to previously described patients with CMT who had GJBl mutations, with a predominantly distal motor and sensory neuropathy in most patients (table 1). Males were more severely clinically affected and had slower MCVs than females. Interestingly, affected members from four families had CNS involvement or deafness, as has been previously described with GJBl mutations. ${ }^{3-4}$ In family 1 , one affected female (patient 1 , table 1) had bilateral extensor plantars but this was probably explained by a second diagnosis of spastic diplegia secondary to prematurity. In family 2 , patient 4 had deafness and abnormal auditory brainstem potentials, and in family 6, patient 12 also had deafness and extensor plantars with no other explanation other than CMT. Patient 5, family 3 had an interesting magnetic resonance image (MRI) of the brain (fig l) with mild but definitely abnormal white matter high signal lesions for her age without any other explanation other than CMT.

\section{DISCUSSION}

CMTX is a common cause of inherited neuropathy. We report six novel mutations of the GJBl gene from six British CMTX families.

The disease onset of the six index patients was usually in later childhood or adolescence with one notable exception. Patient 7, family 3 was noted to have difficulty walking at age 15 months but also had ligamentous laxity. At the age of three years and 10 months his reflexes were present but by age five and a half he was clinically affected with absent reflexes and high arches. He tolerated only limited nerve conduction studies at age five but his ulnar MCV at this stage was $49 \mathrm{~m} / \mathrm{s}$. Similarly, patient 9 , family 5 was definitely affected but his ulnar MCV at age 12 was $51 \mathrm{~m} / \mathrm{s}$. Unfortunately, median MCV was not available.

The clinical features of the neuropathy in our patients were similar to those reported previously in patients with GJBl mutations, including more severe involvement in affected males than in females. Electrophysiological findings fit well with other studies. All patients had motor and sensory involvement electrically, with affected males having upper limb MCVs in the intermediate or demyelinating range (except for the two exceptions mentioned), while affected females tended to have MCVs in the axonal range.

We did find a high incidence of mild CNS involvement and deafness, which has been previously described in patients 
with CMTX, ${ }^{3-15}$ but obviously the patient numbers in our study and particularly the numbers with each mutation are too small to discuss either the prevalence of CNS findings with GJBl mutations or the specificity of CNS findings with particular mutations. It is interesting that GJBl is expressed in the CNS in oligodendrocytes and other neuronal populations. ${ }^{16}$ The MRI findings in patient 5, family 3 are of interest, particularly because she is female. Although the white matter lesions are considered definitely pathological for her age, they are non-specific. Similar MRI findings have been rarely reported with GJBl mutations ${ }^{17-18}$ but the relation of these changes to GJBl mutations has not been established. The findings in our patient are minimal and non-specific but it is of interest that the CNS manifestations in patients with GJB1 mutations are usually mild. It would be of interest to see whether these non-specific but pathological findings are found more frequently in both male and female patients with CMTX with GJBl mutations.

In conclusion, we describe six novel GJBl mutations in patients with CMTX. CMTX secondary to GJBI mutations is now the second commonest cause of CMT. GJBl should be the first gene screened for mutations in all CMT type 1 families who are negative for the chromosome $17 \mathrm{pl} 1.2$ duplication and who have no male to male transmission. This is particularly important in families where males are more severely affected than females, especially if the electrophysiological data suggest that males have MCVs in the demyelinating or intermediate range and females have MCVs in the axonal range, and where there is associated CNS disease. Finally, it is appropriate to consider screening for GJBl mutations in sporadic cases, where the length of the history or the presence of foot deformity raises the possibility of CMT, and especially if the chromosome $17 \mathrm{p} 11.2$ duplication is negative.

\section{ACKNOWLEDGEMENTS}

We thank all patients participating in this study. The work was supported by the Brain Research Trust.

\footnotetext{
Authors' affiliations

M-J Lee, I Nelson, H Houlden, M G Sweeney, N W Wood,

M M Reilly, Department of Molecular Pathogenesis, Institute of

Neurology, Queen Square, London WCIN 3BG, UK

D Hilton-Jones, Department of Neurology, The Radcliffe Infirmary,

Woodstock Road, Oxford OX2 6HE, UK

J Blake, Department of Neurophysiology, National Hospital for

Neurology and Neurosurgery, Queen Square, London WCIN 3BG, UK

Competing interests: none declared
}

Correspondence to: Dr M M Reilly, National Hospital for Neurology and Neurosurgery, Queen Square, London WCIN 3BG;

M.Reilly@ion.ucl.ac.uk

Received 8 January 2002

In revised form 5 April 2002

Accepted 22 April 2002

\section{REFERENCES}

1 Vance JM. Hereditary motor and sensory neuropathies. J Med Genet $1991 ; 28: 1-5$

2 Harding AE, Thomas PK. The clinical features of hereditary motor and sensory neuropathy types I and II. Brain 1980;103:259-80.

3 Nicholson G, Corbett A. Slowing of central conduction in X-linked Charcot-Marie-Tooth neuropathy shown by brainstem auditory evoked responses. J Neurol Neurosurg Psychiatry 1996;61:43-6.

4 Marques JRW, Sweeney MG, Wood NW, et al. Central nervous system involvement in a novel connexin32 mutation affecting identical twins. J Neurol Neurosurg Psychiatry 1999;66:803-4

5 Fischbeck KH, Ar Rushdi N, Pericak-Vance M, et al. X-linked neuropathy: gene localization with DNA probes. Ann Neurol 1986:20:527-32

6 Rozear MP, Pericak-Vance MA, Fischbeck K, et al. Hereditary motor and sensory neuropathy X-linked: a half century follow up. Neurology 1987;37:1460-5.

7 Tabaraud F, Lagrange E, Sindou P, et al. Demyelinting X-linked Charcot-Marie-Tooth disease: unusual eletrophysiological findings. Muscle Nerve 1999;22:1442-7.

8 Hahn AF, Brown WF, Koopman WJ, et al. X-linked dominant hereditary motor and sensory neuropathy. Brain 1990;1 13:1511-25.

9 Senderek J, Bergmann C, Quashoff S, et al. X-linked dominant Charcot-Marie-Tooth disease and related neuropathies: nerve biopsies allow morphological evaluation and detection of connexin-32 mutations (Arg 15Trp, Arg22GIn). Acta Neuropathol 1998;95:443-9.

10 Bergoffen J, Scherer SS, Wang S, et al. Connexin mutations in X-linked Charcot-Marie-Tooth disease. Science 1993;262:2039-42.

11 Bone LJ, Dahl N, Lensch BS, et al. New connexin 32 mutations associated with X-linked Charcot-Marie-Tooth disease. Neurology 1995;45: 1863-6.

12 lonasescu V, Searby C, lonasescu R. Point mutations of the connexin 32 (GJB 1) gene in X-linked dominant Charcot-Marie-Tooth neuropathy. Hum Mol Genet 1994:3:355-8.

13 Sambrook J, Fritsch E, Maniatis T. Purification of nucleic acids. In: Sambrook J, Fritsch E, Maniatis T, eds. Molecular cloning: a laboratory manual, 2nd edn. Cold Spring Harbor: Cold Spring Harbor Laboratory Press, 1989:E3-4.

14 Senderek J, Hermanns B, Bergmann C, et al. X-linked dominant Charcot-Marie-Tooth neuropathy: clinical, electrophysiological, and morphological phenotype in four families with different connexin32 mutations(1). J Neurol Sci 1999;167:90-101.

15 Bahr M, Andres F, Timmerman V, et al. Central visual, acoustic and motor pathway involvement in a Charcot-Marie-Tooth family with an Asn205Ser mutation in the connexin32 gene. J Neurol Neurosurg Psychiary 1999;66:202-6.

16 Rozental R, Giaume C, Spray DC. Gap junctions in the nervous system. Brain Res Rev 2000;32:11-5.

17 Panas M, Karadimas C, Avramopoulos D, et al. Central nervous system involvement in four patients with Charcot-Marie-Tooth disease with connexin32 extracellular mutations. J Neurol Neurosurg Psychiatry 1998:65:947-8.

8 Panas M, Kalfakis N, Karadimas C, et al. Episodes of generalized weakness in two sibs with the C164T mutation of the connexin 32 gene. Neurology 2001;57:1906-8. 